\title{
New Technological Approach in Fabrication of High Purity Nickel Wire Theodor Stuth ${ }^{1, a}$, Rainer Theile ${ }^{1, b^{*}}$ and Oleksandra Krivtsova ${ }^{1, c}$ \\ ${ }^{1}$ Hpulcas GmbH, Frauensteiner Straße 107, 09599 Freiberg, Germany \\ at.stuth@hpulcas.com, ${ }^{b}$ r.theile@hpulcas.com, ${ }^{c}$ o.krivtsova@hpulcas.com
}

Keywords: high purity nickel, wire, cathode plates, hot rolling, trace elements, strengthening behavior.

\begin{abstract}
Hpulcas $\mathrm{GmbH}$ has developed a process of high purity nickel wire manufacturing directly from cathode plates without melting. This means significantly lower capital investments and energy costs as compared to the standard manufacturing technology by melting on the one hand and remaining of the high degree of purity on the other hand. Hpulcas wire is produced by hot rolling of full cathode plates, slitting of plates into sticks, frontal joining and drawing.

High purity nickel has such beneficial properties as micro-cleanliness, excellent mechanical and electrical properties and beneficial corrosion resistance. These properties have been used in batteries and fuel cell components, welding and brazing products, and sensing and controlling instruments.
\end{abstract}

\section{Introduction. Methods of pure nickel primary material production}

Melt metallurgy. A conventional method of pure nickel production is based on a melting process, followed by casting and hot rolling operations. During melting carbon and nickel oxide are added to remove gases [1], silicon is added to decrease the melting point [2], aluminum or titanium are added to deoxidize the melt [3], and manganese or magnesium are added to bond sulfur into globular form [4]. Theoretically, all of those additions should be either outgased or eliminated into a slag. But in practice, this cannot be completely achieved. In addition, small amounts of material from converter's lining and slag spouts could be absorbed by the melt. These are the reasons why standard grades of pure nickel made by melt metallurgy, Ni 200 and Ni 201, have mostly a degree of purity of $99.2 \%$ and $99.6 \%$. By vacuum melting and remelting a higher degree of purity can be obtained. Furnace crucibles however are usually lined with graphite that can result in an increased carbon content of the melt.

Powder metallurgy. Powder obtained by the Mond process [5-8] or by gas/water atomization [910] is compacted by roll compaction followed by controlled atmosphere sintering [11]. Typically for powder technology it is difficult to achieve $100 \%$ density, meaning to avoid any "micro-porosity".

Electrolytic deposition on turning drum. Metal ions are deposited on a turning drum and the deposit is detached as foil [12]. Two sides of the foil have different surface characteristics. This kind of foil is characterized by columnar, brittle grain structure which can be improved by final annealing process. Such deposition process can only be used for low gage strips, not for wires.

Fabrication from cathode plates. Full cathode plates are used as primary material in the process described in the present paper. Wire is produced by hot rolling of full cathode plates, slitting of plates into sticks, frontal joining by welding and drawing.

\section{Materials and methods}

During refinement of nickel, cathode plates with a purity of $99.98 \%$ are produced. Currently, these cathode plates are cut into squares and dissolved during electrolytic plating of nickel or melted to produce stainless steels. In the hpulcas process [13] full-scale nickel cathode plates are used as a primary material. These $12-15 \mathrm{~mm}$ thick primary plates are characterized by some special geometric and structural features, which have to be considered before starting the next process steps. Hpulcas 
has developed suitable surface treatment and heat treatment steps in order to prepare sheets for the following hot rolling process.

Primary plates are annealed and rolled at the same temperature up to thickness of about $6 \mathrm{~mm}$. This process is necessary for improving the microstructure and optimizing of cross profile and surface condition. After cooling, the plates of about $2000 \mathrm{~mm}$ long are levelled and brushed to remove the oxides left from the annealing process.

After hot rolling to $6 \mathrm{~mm}$ the plates are cut into strips of $6 \mathrm{~mm}$ width having a polygonal cross section as a square cross section is not suitable for drawing of round wires. Cut sticks are frontally hot or cold welded. Oxidation of the ends of joined sticks is excluded by a pressure welding. The welding zones from joining of cathode sticks have the same chemical composition as the primary material. Burrs resulting from pressure welding are removed.

\section{Analyses of hpulcas technology aspects}

Trace elements. One of the specific characteristics of nickel is the great dependence of its properties on the degree of purity. Apart from the properties, especially for sensing and regulating applications, the reproducibility of properties is important. This is guaranteed by low content of trace elements, which has a decisive influence on properties. As a result, even if nickel wire made by melt metallurgy meets the standards, a number of trace elements and their actual content may largely differ from melt to melt. Therefore, the approach of pure nickel fabrication developed by hpulcas is beneficial to other methods allowing production of high purity nickel with minimum content of trace elements.

Typical trace elements and their contents for different grades of pure nickel including hpulcas pure nickel Ni99.98\% are represented in Table 1.

Table 1. Typical trace elements and their contents for different grades of pure nickel

\begin{tabular}{|c|c|c|c|c|c|c|c|c|c|}
\hline & Ni 99.2 & Ni 99.6 & Ni 99.8 & Ni 99.98 & & Ni 99.2 & Ni 99.6 & Ni 99.8 & Ni 99.98 \\
\hline $\mathrm{Ni}[\%]$ & 99.35 & 99.7 & 99.8 & 99.98 & $P[\%]$ & 0,003 & $<0,002$ & $<0,002$ & 0,009 \\
\hline $\mathrm{C}[\%]$ & 0.05 & 0.03 & 0.03 & 0.002 & $\operatorname{Mn}[\%]$ & 0.066 & 0.01 & $<0.002$ & $<0.0002$ \\
\hline $\mathrm{S}[\%]$ & & 0.001 & & $<0.0002$ & $\operatorname{Mg}[\%]$ & 0.01 & 0.01 & 0.01 & $<0.0002$ \\
\hline $\mathrm{Si}[\%]$ & 0.13 & 0.07 & 0.08 & $<0.002$ & $\operatorname{Ti}[\%]$ & 0.045 & $<0.02$ & $<0.002$ & $<0.0002$ \\
\hline \multirow[t]{2}{*}{$\mathrm{Fe}[\%]$} & 0.22 & 0.14 & 0.06 & 0.00017 & $\mathrm{Cu}[\%]$ & 0.1 & 0.003 & 0.01 & $<0.0002$ \\
\hline & & & & & Co[\%] & & 0.003 & 0.01 & $<0.0002$ \\
\hline
\end{tabular}

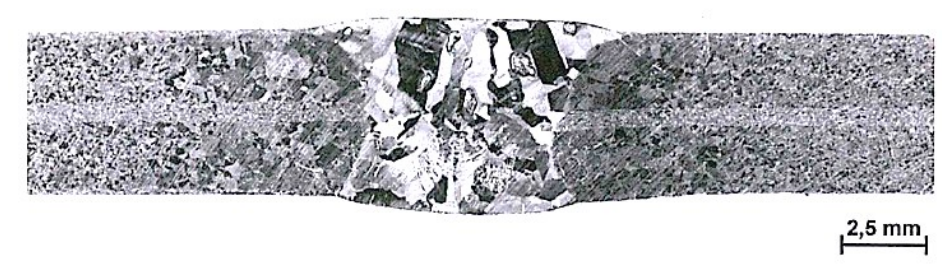

(a)

(b)

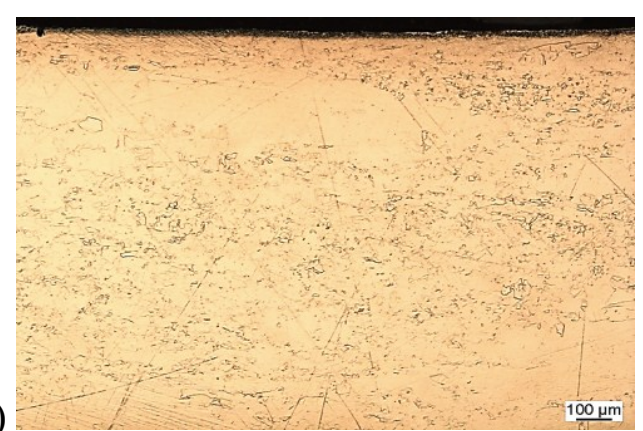

Fig.1. Weld joint (hpulcas nickel plate material) after welding (a) and after $70 \%$ deformation and heat treating $\left(300^{\circ} \mathrm{C} / 1\right.$ hour $)(b)$ 
Weld joint. Initially, grain structures of welding zone, heat affected zone and parent material differ from each other. After being reduced by rolling in total by about $70 \%$ and annealed, structural difference is no longer detectable. Weld joint structure is represented in Fig. 1 in as-welded (a) and heat treated (b) conditions.

After these process steps wire can be drawn like a rolled wire.

Strengthening behavior. Fig. 2 shows the correlation between reduction of wire and increase in strength, hardness as well as change of elongation values. It is evident that by proper processing, a wide range of conditions from very soft to quite hard can be achieved. Although after reduction of about $75 \%$ the elongation value drops to about $1.5 \%$, wire can be further reduced up to $98 \%$ without breaking.
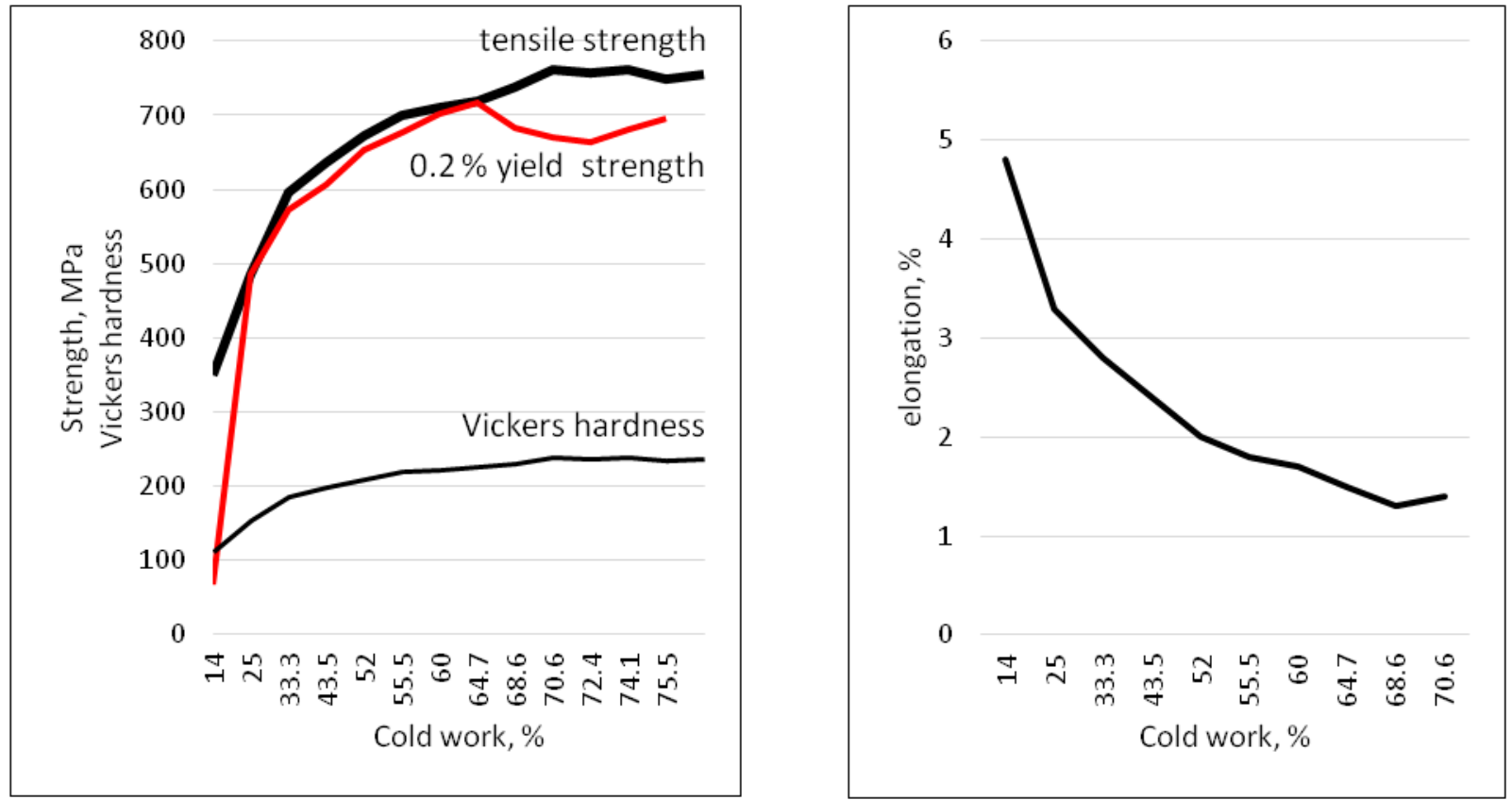

Fig.2. Strengthening behavior of $\mathrm{Ni} 99.98 \%$ depending on the cold rolling reduction degree

Range of mechanical properties. Even though high purity nickel made by powder metallurgy can be produced having the same degree of purity as hpulcas wire, comparison of the mechanical properties shows that hpulcas nickel wire made from cathodes is softer in all tempers. Table 2 represents the comparison of the range of mechanical properties, such as tensile strength $\left(\mathrm{R}_{\mathrm{m}}\right), 0.2 \%$ yield strength $\left(\mathrm{R}_{0.2}\right)$, elongation and Vickers hardness for hpulcas high purity nickel wire produced by means of powder metallurgy.

Table 2. Range of typical mechanical properties for hpulcas Ni $99.98 \%$ wire and powder metallurgy wire [14]

\begin{tabular}{llcccc}
\hline Condition & Process & $\begin{array}{c}\mathbf{R}_{\mathbf{0 . 2}} \\
{[\mathbf{M P a}]}\end{array}$ & $\begin{array}{c}\mathbf{R}_{\mathbf{m}} \\
{[\mathbf{M P a}]}\end{array}$ & $\begin{array}{c}\text { Elongation } \\
{[\mathbf{\%}]}\end{array}$ & $\begin{array}{c}\text { Hardness } \\
{[\mathbf{H V}]}\end{array}$ \\
\hline \hline \multirow{2}{*}{$\begin{array}{l}\text { Soft } \\
\text { annealed }\end{array}$} & Hpulcas process & $100-200$ & $300-350$ & $>45$ & $<65$ \\
& Powder metallurgy & $105-140$ & $345-400$ & $40-45$ & $64-90$ \\
\multirow{2}{*}{ Half hard } & Hpulcas process & $>300$ & $>450$ & $>15$ & $>100$ \\
& Powder metallurgy & $345-520$ & $413-550$ & $79-86$ & $148-171$ \\
\hline \multirow{2}{*}{ Full hard } & Hpulcas process & $>500$ & $600-900$ & $>5$ & $>150$ \\
& Powder metallurgy & $620-690$ & $650-710$ & 12 & $>203$ \\
\hline
\end{tabular}

An excellent forming behavior of high purity nickel in the annealed condition allows cold reduction of maximum $98 \%$ without an intermediate annealing. 
Corrosion resistance. High purity and cleanliness of Ni $99.98 \%$ results in a very dense oxide layer, which provides an excellent corrosion resistance even at elevated temperatures. A typical oxide layer on $\mathrm{Ni} 99.98 \%$ is represented in Fig. 3. Because of such a layer, high purity nickel shows excellent corrosion resistance to many corrosion medias such as water, acids, alkalis, salts, fluorine and chlorine [15].

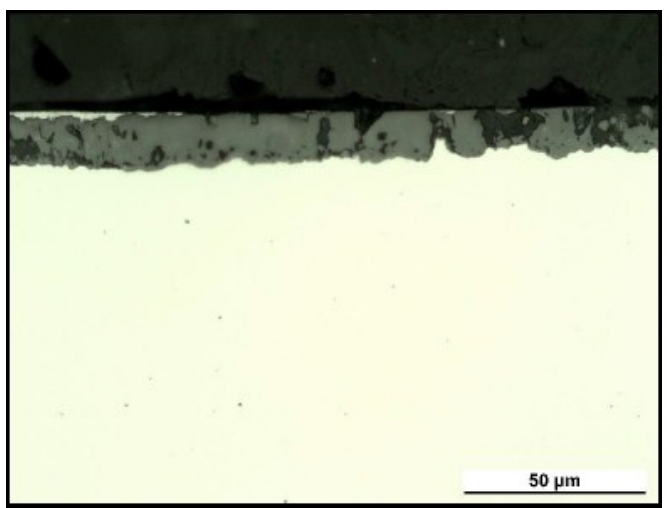

Fig.3. Oxide layer on $\mathrm{Ni} 99.98 \%$ after heat treatment $\left(1100^{\circ} \mathrm{C}, 1 \mathrm{~h}\right)$

Other properties. Along with the above mentioned properties of Ni $99.98 \%$ several others could be mentioned:

- Higher electrical conductivity in comparison with the standard grades, such as Ni 99.2 and $\mathrm{Ni} 99.6-1.2 * 107 \mathrm{~S} / \mathrm{m}$ for Ni $99.98 \%$ comparing to the physical value of $1.43 * 107 \mathrm{~S} / \mathrm{m}[16]$;

- Narrow tolerance of the Curie temperature: for pure nickel it is $358.28^{\circ} \mathrm{C}$ [17].

\section{Conclusions}

A new process of high purity nickel wire manufacturing directly from cathode plates without melting was introduced in the present paper. The proposed hpulcas process for pure nickel wire fabrication allows to produce wire with exceptional physical and mechanical properties. This method is shown to be valuable for manufacturing of lead wire for conducting electricity in aggressive environmental conditions like batteries or capacitors; production of high purity nickel used as diffusion barrier in roll bonding as well as wire used in fabrication of temperature sensors and thermosensitive resistors, e.g. control coils.

\section{Summary}

Hpulcas patented method for high purity nickel wire fabrication from cathode plates has been represented. Strengthening behavior as well as comparison of hpulcas nickel material with high purity nickel made by another manufacturing technique has been provided. High purity nickel having a range of excellent physical and mechanical properties has been proved to be suitable for many fields of application such as electrical and high precision devices.

\section{References}

[1] S. J. Rosenberg, Nickel and its alloys, Washington, 1968, p. 50

[2] S. J. Rosenberg, Nickel and its alloys, Washington, 1968, p. 49

[3] W. Betteridge, Nickel and its alloys, New York, 1984, p. 138

[4] R. Fleitmann, Darstellung von walz- und schmiedbarem Flußnickel und dessen Legierungen, Patent DE 73423A

[5] L. Mond, C. Langer, F. Quincke, Action of carbon monoxide on nickel, J. Chem. Soc. Trans. 57 (1890) 749-753 
[6] L. Mond, The History of My Process of Nickel Extraction, J. Soc. Chem. Ind. 14 (1895) 945946

[7] N/A, The Extraction of Nickel from its Ores by the Mond Process, Nature 59 (1898) 1516, 6364

[8] L. Mond, A process for obtaining metallic nickel from nickel carbonyl, and apparatus therefor, Patent GB189801106A

[9] L. V. M. Antony, R. G. Reddy, JOM 55 (2003) 14-18

[10] Y. Seki, S. Okamoto, H. Takigawa, N. Kawai, Metal Powder Report 45 (1990) 1, 38-40

[11] http://www.ametek-ct.com/high-purity-metal-strip.html

[12]R. Parkinson, Electroforming - a unique metal fabrication process, Nickel Development Institute, NiDI Technical Series No 10 084, 1998, pp. 2 - 5

[13] T. Stuth, Method for producing a nickel strip, Patent US9003641B2

[14] http://www.ametek-ct.com/pdf/tech/High-Purity-Nickel-Datasheet.pdf

[15] http://www.specialmetals.com/assets/documents/alloys/nickel-duranickel/nickel-200-201.pdf

[16]http://periodictable.com/Properties/A/ElectricalConductivity.an.html

[17]B. Legendre, M. Sghaier, Journal of Thermal Analysis and Calorimetry 105 (2011) 1, 141-143 